\title{
A assistência estudantil no processo educacional: possibilidades de atuação
}

\author{
Priscila da Silva Soares ${ }^{1}$ \\ ORCID: 0000-0002-8807-1916 \\ Cledir de Araújo Amaral ${ }^{1}$ \\ ORCID: 0000-0002-7221-5364
}

\section{Resumo}

A assistência estudantil se constituiu apoio aos estudantes para sua permanência na instituição educacional pública de nível superior devido às dificuldades financeiras dos jovens que geralmente se deslocavam de suas cidades de origem para estudar em outros locais. Entretanto, atualmente, novas atribuições são delegadas à assistência estudantil de modo a contribuir para o processo educacional numa perspectiva omnilateral. Este artigo tem o objetivo de levantar as possibilidades de atuação dos profissionais da assistência estudantil na educação formal na sociedade contemporânea. Para tanto, utilizamos a pesquisa bibliográfica e documental como estratégia de levantamento de dados. Identificamos que as possibilidades de atuação da assistência estudantil perpassam por dois modelos básicos. 0 primeiro, pautado em uma política seletiva, de cunho apenas financeiro, que reflete em uma educação não emancipadora. 0 segundo, de caráter universal, atende 0 estudante em diversos aspectos: econômico, social, acadêmico e humano. Entendemos esse último modelo como fruto da crescente exigência social contemporânea e da consequente emergência de outras demandas que repercutem no desempenho acadêmico e interferem na permanência dos estudantes de diferentes níveis de ensino. Para tanto, novas funções podem ser atribuídas à assistência ao estudante enquanto atividade meio para garantir o sucesso do processo educacional numa perspectiva omnilateral.

\section{Palavras-chave}

Ensino multidimensional - Assistência estudantil - Permanência - Formação cidadã.

1- Instituto Federal do Acre, Rio Branco, AC, Brasil. Contatos: priscila.soares@ifac.edu.br; cledir.amaral@ifac.edu.br. 


\section{Student assistance in the educational process: possibilities of performance*}

\section{Abstract}

Student assistance was constituted as support for students to remain in public higher education institutions, due to the financial difficulties of young people who usually moved from their hometowns to study elsewhere. Nowadays, however, new attributions have been delegated to student assistance to contribute to the educational process from an omnilateral perspective. This article aims to raise the possibilities of performance of student assistance professionals of formal education in contemporary society. To do so, bibliographic, and documental research was used as a strategy for data survey. We have identified that the possibilities of performance of student assistance run through two basic models: the first one is based on a selective policy, with a financial nature only, which reflects on a non-emancipating education; and the second one, of a universal nature which assists the student in several aspects: economic, social, academic, and human development. We understand this latter model because of the growing demands of today's society and the consequent rise of other demands which impact academic performance and interfere with the permanence of students from different levels of education. Therefore, new roles can be attributed to student assistance to ensure the success of the educational process from an omnilateral perspective.

\section{Keywords}

Multidimensional education - Student assistance - Permanence - Citizenship formation.

\section{Introdução}

A escola, enquanto ambiente educacional e espaço de formação humana, exerce importante função social, que pode se configurar como lugar de reprodução das relações de poder e dominação de classes ou como lugar de emancipação e rompimento com essa lógica. Para Borges (2017), se a escola não se compromete com o enriquecimento humano no sentido da humanização, ela contribui, ao máximo, para a lógica do capitalismo, que se revela na alienação da classe trabalhadora.

A escola é reconhecida como uma expressão da sociedade, cujos estudantes pertencentes à classe trabalhadora ou sujeitos oriundos das classes populares apresentam historicamente maiores dificuldades de acesso e de permanência, sendo necessária a superação de tais dificuldades, por meio de ações que viabilizem a democratização tanto do acesso como da permanência no cotidiano acadêmico escolar. É nessa busca de mecanismos de equalização social, ante as desigualdades oriundas do modo de produção capitalista, que a assistência estudantil foi concebida enquanto atividade meio do processo educacional (NASCIMENTO, 2014). 
Nessa perspectiva, o Decreto ${ }^{\circ} 7.234$, de 19 de julho de 2010, que trata do Programa Nacional de Assistência Estudantil (Pnaes), apresenta-se como elemento que visa contribuir para os processos educacionais, focado, inicialmente, nas dificuldades financeiras que repercutem na permanência e no êxito dos discentes, pois "é sabido que alunos de baixa condição socioeconômica acabam abandonando o curso em decorrência da insuficiência de recursos financeiros para sua manutenção" (FONAPRACE, 2012, p. 109).

Por outro lado, ao reconhecermos que a evasão e a retenção têm outros determinantes além das questões de cunho financeiro, que podem variar de acordo com o nível de ensino, nos quais a atuação da equipe técnica da assistência estudantil pode ter atribuição promissora para colaborar com o sucesso escolar, questionamos: quais as possibilidades de atuação da equipe técnica de assistência estudantil nesse contexto?

Com o intuito de responder a esse questionamento, sem a pretensão de esgotá-lo, este estudo tem como objetivo discutir as possibilidades de atuação da equipe técnica de assistência estudantil para o processo educacional no sentido de uma formação omnilateral do sujeito.

\section{Procedimentos metodológicos}

Trata-se de um estudo de revisão integrativa da literatura centrado na assistência estudantil, nos processos educacionais e na formação omnilateral, que reúne autores precursores e contemporâneos de tais temáticas, assim como documentos e regulamentos relativos a programas de assistência estudantil no Brasil, com uma abordagem qualitativa e tipologia exploratória.

Realizamos pesquisa em livros consagrados e em outras publicações acadêmicas submetidas à avaliação por pares, disponíveis nas plataformas de busca SciElo e Google Acadêmico. A busca desses artigos se deu a partir dos descritores: assistência estudantil; processo educacional; assistência estudantil e processo educacional; evasão escolar; permanência e êxito.

A fim de elencar possibilidades de atuação dos profissionais da assistência estudantil, especialmente nos Institutos Federais (IFs), analisamos o Decreto $n^{0}$ 7.234/2010, que regulamenta o Programa de Assistência Estudantil no Brasil, a Lei no 9.394, que estabelece as Diretrizes e Bases da Educação Nacional (BRASIL, 1996), e, por fim, para ter um panorama da realidade regional, buscamos as políticas institucionais que regulamentam a assistência estudantil nos sete IFs da região Norte, a saber: Acre, Resolução Consu/ Ifac n ${ }^{\circ}$ 035/2018 (IFAC, 2018); Amapá, Resolução no 31/2019/Consup/Ifap (IFAP, 2019); Amazonas, Resolução n 13/2011-Consup/Ifam (IFAM, 2011); Pará, Resolução ${ }^{\circ}$ 07/2020-Consup (IFAP, 2020); Rondônia, Resolução n 23/2018/Reit - Consup/Ifro (IFRO, 2018); Roraima, Resolução no 486/2020 - Conselho Superior (IFRR, 2020); e Tocantins, Resolução n 22/2014/Consup/IFTO (IFT0, 2014).

\section{O processo educacional formal na sociedade contemporânea}

0 processo educacional deve ser compreendido amplamente, tendo em vista que engloba todos os processos de descoberta do mundo e a construção da base cognitiva e 
afetiva desde o primeiro núcleo formador de cada indivíduo: a família. Posteriormente, passa por instituições de ensino, mercado de trabalho, ambientes religiosos, sindicais, entre outros (MAGALHÃES, 2004).

De acordo com Magalhães (2004), a distinção entre processo educacional e processo educacional formal reside no ambiente, em que o último se realiza em instituições de educação formal, os espaços construídos justamente com essa finalidade que são responsáveis por essa formação. Compreendemos existir um movimento de inter-relação de pessoas e áreas de conhecimento nesses locais: "estudantes, professores, funcionários, pais e gestores, com seus saberes, éticas, emoções e compromissos políticos e pedagógicos que constituem a escola" (BOCK et al., 2016, p. 230).

Com a expansão da escolarização, observa-se que, além de serem instruídas por professores, as pessoas precisam ser educadas por educadores, "compreendendo-se que todos os que têm presença permanente no ambiente escolar, em contato com os estudantes, são educadores, independentemente da função que exerçam” (BRASIL, 2004, p. 16), e, portanto, têm a capacidade de elaborar propostas para o aprimoramento da educação. Esse entendimento colabora para a percepção do traço pedagógico intrínseco às funções do trabalhador não-docente, redimensionando sua importância e sua atuação educativa em termos sociais e profissionais (BEZERRA et al., 2010; BRASIL, 2004).

Cada membro da comunidade escolar tem sua função no processo educacional, já que a educação ocorre, também, a partir das relações sociais e a aprendizagem envolve a aquisição de informações, habilidades e valores socialmente relevantes. De forma complementar à atuação do professor em sala de aula, ocorrem importantes processos educativos nos demais ambientes da escola. A troca de experiências e a vivência coletiva evidenciam o trabalho dos educadores não-docentes, denominados funcionários da escola (BRASIL, 2004). Nas universidades e institutos federais correspondem aos técnicos administrativos em educação, mas acreditamos que os demais servidores terceirizados, como os prestadores de serviços de limpeza, de vigilância, de portaria, recepção e estagiários que lidam frequentemente com os estudantes sejam também corresponsáveis por importantes processos educacionais.

Essa nova forma de compreender o processo educacional formal visa ampliar a concepção de educação, pois considera a diversidade no contexto escolar tanto entre os educadores quanto entre os educandos, assim como as particularidades de cada estudante. Para Zabala (1998, p. 28), "[...] educar quer dizer formar cidadãos e cidadãs, que não estão parcelados em compartimentos estanques, em capacidades isoladas”. Dessa forma, as aprendizagens dependem das características específicas de cada um dos aprendizes, conforme as experiências vividas desde o nascimento. A maneira e o ritmo da aprendizagem variam segundo capacidades, incentivos e interesses de cada um, ou seja, resultam de processos singulares e pessoais (ZABALA, 1998).

De acordo com Morin (2011, p. 35), sobre os princípios do conhecimento pertinente, a sociedade e o ser humano são multidimensionais, uma vez que este é "[...] ao mesmo tempo biológico, psíquico, social, afetivo e racional, já a sociedade comporta as dimensões histórica, econômica, sociológica, religiosa [...]”. O conhecimento deve considerar todos 
esses aspectos, pois estão intrinsecamente interligados e não podem isolar uma parte da outra, tanto na relação individual humana quanto na sociedade. A educação deve promover uma inteligência que considere esse multidimensionamento dentro de uma perspectiva complexa, contextual e global, visto que existe uma inter-relação direta entre indivíduo-sociedade-espécie, em que cada ente é, simultaneamente, meio e fim, ou seja, "[...] a cultura e a sociedade garantem a realização dos indivíduos e as interações entre os indivíduos permitem a perpetuação da cultura e a auto-organização da sociedade" (MORIN, 2011, p. 49).

Desta forma, verifica-se a interligação do desenvolvimento individual com as relações sociais, contexto no qual a escola está inserida, sendo desafiada constantemente a atender essas especificidades individuais num contexto social amplo. Libâneo (2012) ressalta a busca de um tipo de escola que disponha de espaços e tempo para atender às necessidades básicas de aprendizagem, com foco no desenvolvimento humano. Trata-se de uma escola que, ao mesmo tempo em que promova o domínio do saber sistematizado e o desenvolvimento de capacidades intelectuais, assegurando o direito à igualdade, considere que essa função se destina a diferentes sujeitos, tendo em vista que a diferença é condição explícita do ser humano e, consequentemente, das situações educativas.

Na sociedade contemporânea, muito tem se discutido sobre a concepção de uma educação cidadã que se afaste de modelos pedagógicos padronizados e excludentes, em favor de um ambiente de aprendizagens colaborativas e interativas que considerem todos os integrantes da escola como protagonistas do processo educativo. 0 entendimento desse conceito implica na reflexão sobre a nova função social da escola e, por consequência, sobre a nova função pedagógica de seus profissionais (BRASIL, 2004).

Nesse sentido, destacamos a compreensão de omnilateralidade em Marx, que pressupõe uma formação integral crítica e que atenda a todas as necessidades do ser humano, na qual o indivíduo não seja apenas assimilador e reprodutor de informações, mas que desenvolva conhecimentos e habilidades para que seja autor da sua história e sujeito crítico e participativo na sociedade (COSTA; COUTINHO, 2018).

Entretanto, apesar de haver certo consenso entre os educadores quanto à importância de seu papel e o reconhecimento de uma função social creditada à escola, paradoxalmente, as diferentes intepretações sobre os processos de aprendizagem e de formação se configuram como um desafio no cotidiano educacional. É necessário refletir sobre a prática profissional no processo educativo considerando sua complexidade e as dificuldades de mensurar os fatores de tal processo, podendo citar, dentre eles, os "parâmetros institucionais, organizativos, tradições metodológicas, possibilidades reais dos professores, dos meios e condições físicas existentes” (ZABALA, 1998, p. 16). Dessa forma, a prática educativa se apresenta como algo fluido, difícil de demarcar com conceitos básicos, pois há a expressão de diversos fatores e hábitos pedagógicos solidificados que são difíceis de romper (ZABALA, 1998).

0 papel atribuído ao ensino tem priorizado as capacidades cognitivas que são consideradas mais relevantes e que correspondem à aprendizagem das disciplinas ou matérias tradicionais, ainda com cunho meritocrático. Para Zabala (1998), se considerarmos 
que cabe à escola atender ao desenvolvimento das demais capacidades do sujeito e promover a formação integral dos estudantes, é preciso defınir urgentemente um princípio geral, que responda ao que se deve compreender por autonomia e equilíbrio pessoal e o que se quer dizer por atuação ou inserção social.

Ao questionar essa função da escola e explanar a necessidade de definição de um princípio geral e parâmetros para essa nova forma de ensinar, Zabala (1998) traz à luz algumas problemáticas que se manifestam em uma sociedade desigual, já que, apesar de haver várias teorias e estudos sobre o conhecimento e a importância da formação integral do ser humano, os ambientes escolares ainda são elaborados na perspectiva de reprodução dos padrões hegemônicos da sociedade. A sociedade brasileira ainda é incipiente quando o assunto é formar indivíduos críticos cujos pensamentos sejam conduzidos por si mesmos (MAGALHÃES, 2004).

Bock et al. (2016, p. 241) reforçam essa questão:

Apesar de alguns jovens referirem-se à escola como a base de sua aprendizagem, essa base não é associada a uma apropriação crítica do conhecimento, mas a um conhecimento instrumental básico para a inserção no mundo do trabalho e do consumo e regido por parâmetros de caráter mercadológico.

Por outro lado, para esses autores, apesar de a escola ainda ser um lugar de reprodução da desigualdade social, é também espaço promissor para empreender ações focadas na superação das diferenças. É nessa perspectiva que defendemos a atuação dos profissionais da assistência estudantil, embora reconheçamos que a atenção inicial da assistência estudantil esteja centrada, principalmente, em ações de cunho financeiro, prescindindo de ações que considerem os fatores sociais diversos nos quais estão inseridos os estudantes, exigindo ações de abrangência ampliada.

\section{Assistência estudantil e processo educacional}

No Brasil, em 1931, no governo Vargas, foram propostas medidas de beneficência aos discentes universitários reconhecidos como pobres, que receberiam bolsas de estudos, inicialmente por meio de auxílios para alimentação e moradia. Assim, teve origem a assistência estudantil, uma modalidade de assistência social executada nas instituições de ensino superior com o intuito de garantir apoio ao estudante carente sua permanência no curso (NASCIMENTO, 2014; TAUFICK, 2014).

Desde então, ocorreram muitas lutas de estudantes para a manutenção e a ampliação desse programa, bem como e várias reformulações até chegar ao Decreto $\mathrm{n}^{\circ}$ 7.234, de 19 de julho de 2010, que regulamenta o Programa Nacional de Assistência Estudantil nas Instituições Federais de Ensino Superior (IFES) (NASCIMENTO, 2014). A seguir, elencamos as principais reformulações ocorridas na assistência estudantil no Brasil desde as primeiras ações em 1931. 
Quadro 1 - Linha do tempo das Políticas de Assistência Estudantil no Brasil

\begin{tabular}{|c|c|c|}
\hline Decreto ou Lei & Característica & Público-alvo \\
\hline $\begin{array}{llll}\text { Decreto } & n^{0} & 19.851 & \text { (BRASIL, } \\
\text { 1931) } & & & \\
\end{array}$ & $\begin{array}{l}\text { Previa concessão de bolsa de estudos e serviço de atendimento } \\
\text { médico e hospitalar ao corpo discente. }\end{array}$ & Todos os estudantes \\
\hline $\begin{array}{l}\text { Constituição da República } \\
\text { dos Estados Unidos do Brasil } \\
\text { (BRASIL, 1934) }\end{array}$ & $\begin{array}{l}\text { Previa que a União, os estados e o Distrito Federal deveriam } \\
\text { reservar parte dos patrimônios territoriais para formação de } \\
\text { fundos para a educação e que parte dele deveria ser aplicado } \\
\text { em auxílios, por meio de fornecimento de material escolar, bolsa } \\
\text { de estudo, assistência alimentar, dentária e médica, e para } \\
\text { vilegiaturas. }\end{array}$ & Alunos necessitados \\
\hline $\begin{array}{l}\text { Constituição dos Estados Unidos } \\
\text { do Brasil (BRASIL, 1946) }\end{array}$ & $\begin{array}{l}\text { Regulamentava que cada sistema de ensino teria, obrigatoriamente, } \\
\text { serviços de assistência educacional que assegurassem condições } \\
\text { de eficiência escolar aos alunos necessitados. }\end{array}$ & Alunos necessitados \\
\hline $\begin{array}{l}\text { Lei de Diretrizes e Bases da } \\
\text { Educação Nacional } n^{0} 4.024 \\
\text { (BRASIL, 1961) }\end{array}$ & $\begin{array}{l}\text { Previa assistência social, médico-odontológico e de enfermagem } \\
\text { aos alunos. }\end{array}$ & Todos os estudantes \\
\hline $\begin{array}{l}\text { Lei de Diretrizes e Bases da } \\
\text { Educação Nacional } n^{\circ} 5.692 \\
\text { (BRASIL, 1971) }\end{array}$ & $\begin{array}{l}\text { Previa assistência educacional que assegurasse aos alunos } \\
\text { eficiência escolar. Incluía auxílios para aquisição de material } \\
\text { escolar, transporte, vestuário, alimentação, tratamento médico e } \\
\text { dentário e outras formas de assistência familiar. }\end{array}$ & Alunos necessitados \\
\hline $\begin{array}{l}\text { Decreto } n^{0} \quad 69.927 \quad \text { (BRASIL, } \\
\text { 1972) }\end{array}$ & $\begin{array}{l}\text { Instituía o Programa Bolsa de Trabalho com o objetivo de } \\
\text { proporcionar a estudantes de todos os níveis de ensino } \\
\text { oportunidades de exercício profissional em órgãos ou entidades } \\
\text { públicas ou particulares. }\end{array}$ & $\begin{array}{l}\text { Estudantes carentes de recursos } \\
\text { financeiros }\end{array}$ \\
\hline $\begin{array}{l}\text { Constituição da República } \\
\text { Federativa do Brasil (BRASIL, } \\
\text { 1988) }\end{array}$ & $\begin{array}{l}\text { Prevê, como dever do Estado, a garantia de atendimento ao } \\
\text { educando, em todas as etapas da educação básica, por meio } \\
\text { de programas suplementares de material didático-escolar, } \\
\text { transporte, alimentação e assistência à saúde. } \\
\end{array}$ & Todos os alunos \\
\hline $\begin{array}{l}\text { Lei de Diretrizes e Bases da } \\
\text { Educação Nacional } n^{\circ} 9.394 \\
\text { (BRASIL, 1996) }\end{array}$ & $\begin{array}{l}\text { Traz o mesmo texto da Constituição Federal em relação ao dever } \\
\text { do Estado de garantir o atendimento do educando a programas } \\
\text { suplementares de material didático-escolar, transporte, } \\
\text { alimentação e assistência à saúde. }\end{array}$ & Todos os alunos \\
\hline $\begin{array}{l}\text { Portaria do Ministério da } \\
\text { Educação } n^{0} 39 \text { (BRASIL, 2007) }\end{array}$ & Instituía o Programa Nacional de Assistência Estudantil (Pnaes). & $\begin{array}{l}\text { Estudantes de cursos de graduação } \\
\text { presenciais e selecionados por meio de } \\
\text { análise socioeconômica }\end{array}$ \\
\hline $\begin{array}{llll}\text { Decreto } & n^{0} \quad 7.234 & \text { (BRASIL, } \\
\text { 2010) } & & & \end{array}$ & $\begin{array}{l}\text { Dispõe sobre o Programa Nacional de Assistência Estudantil. Prevê } \\
\text { que as ações de assistência estudantil devem viabilizar a igualdade } \\
\text { de oportunidades, contribuir para a melhoria do desempenho } \\
\text { acadêmico e agir, preventivamente, nas situações de retenção e } \\
\text { evasão decorrentes da insuficiência de condições financeiras. }\end{array}$ & $\begin{array}{l}\text { Jovens da educação superior pública } \\
\text { federal prioritariamente oriundos de } \\
\text { escola pública e com renda familiar } \\
\text { per capita de até um salário-mínimo } \\
\text { e meio. Inclui os institutos federais e } \\
\text { suas especificidades. }\end{array}$ \\
\hline $\begin{array}{l}\text { Projeto de Lei da Câmara dos } \\
\text { Deputados } n^{0} 1.270 \text { (BRASIL, } \\
\text { [2015]) }\end{array}$ & $\begin{array}{l}\text { Dispõe sobre o Programa Nacional de Assistência Estudantil. } \\
\text { Torna o decreto anterior em lei. } \\
\text { (Ainda em tramitação no Congresso Nacional). }\end{array}$ & $\begin{array}{l}\text { Traz pequenas diferenças em relação ao } \\
\text { texto do decreto, dentre elas a inclusão } \\
\text { do atendimento aos estudantes de pós- } \\
\text { graduação. Amplia a prioridade para } \\
\text { estudantes cotistas, negros, indígenas, } \\
\text { mulheres e parte da comunidade } \\
\text { LGBTTT (Lésbicas, Gays, Bissexuais, } \\
\text { Travestis, Transexuais e Transgêneros). }\end{array}$ \\
\hline
\end{tabular}

Fonte: Adaptado de Antunes (2018). 
Observamos que, com o tempo, foi se expandindo o rol de ações de assistência estudantil a serem ofertadas aos discentes, visto que os regulamentos anteriores focavam em ações de saúde, material escolar, alimentação e moradia. Porém, a partir de 2007, o rol de atendimento se ampliou para nove categorias, incluindo cultura e esporte.

0 Decreto $n^{0} 7.234 / 2010$ regulamenta dez possibilidades de ações nas áreas de alimentação, moradia estudantil, transporte, atenção à saúde, inclusão digital, cultura, esporte, creche, apoio pedagógico e acesso, participação e aprendizagem de estudantes com deficiência, transtornos globais do desenvolvimento, altas habilidades e superdotação (BRASIL, 2010). Para tanto, anualmente, o governo federal destina recurso específico para custear essas ações nas IFES.

Apesar da prerrogativa de atendimento das demandas, especialmente de cunho financeiro destacada no artigo $4^{\circ}$ do referido decreto, o qual afırma que as ações de assistência estudantil devem "considerar a necessidade de viabilizar a igualdade de oportunidades, contribuir para a melhoria do desempenho acadêmico e agir, preventivamente, nas situações de retenção e evasão decorrentes da insuficiência de condições financeiras" (BRASIL, 2010). A partir de uma perspectiva crítica da realidade, verificam-se outros aspectos que também afetam o desempenho acadêmico e podem ocasionar a evasão, dentre eles, a dificuldade de compreensão dos conteúdos das disciplinas, o uso ou abuso de álcool e outras drogas, gravidez não planejada, além de violência familiar e urbana (TAUFICK, 2014).

Figueiredo e Salles (2017) e Silva e Nogueira (2016) destacam ainda a não identificação com o curso, dificuldades em obter êxito nas avaliações, influência familiar, dilema entre trabalho e estudo, deficiências na formação escolar antecedente, práticas de avaliação por vezes classificatórias e excludentes, relações interpessoais no ambiente educacional fragilizadas ou conflituosas, influência de amigos, questões relativas à estrutura e políticas escolares, oportunidades e desinteresse institucional e/ou governamental como outros fatores que podem ocasionar evasão.

Por outro lado, em relação aos fatores que podem contribuir para a permanência, Silva e Nogueira (2016) apontam as experiências pessoais anteriores ao ingresso, ao que se tem como projeção da vida futura, "maior avanço no percurso acadêmico, recebimento de bolsas, boas notas, participação em programa de nivelamento" (SILVA; NOGUEIRA, 2016, p. 122), ou seja, a permanência envolve fatores materiais e simbólicos que podem corresponder a interesses e desejos do estudante, a relacionamentos estabelecidos no ambiente escolar, a situações pessoais e/ou familiares e a fatores socioeconômicos e culturais relacionados àqueles estudantes em condição econômica vulnerável.

Podemos destacar, ainda, outras necessidades apresentadas pelos estudantes abordados por Andrade (2017), como desenvolver condições para pensar sua identidade pessoal e profissional, imaginar e planejar seu futuro, permitindo estabelecer planos equivalentes à sua realidade, com o objetivo de superar a condição de vulnerabilidade. Desta forma, Taufick (2014) sugere que a assistência estudantil deve ser discutida considerando múltiplas funções: social, pedagógica e psicológica.

Andrade (2017) entende o desenvolvimento psicossocial do estudante como um importante indicador de reconhecimento pessoal e da participação social, já que a visão agregada da função de si e dos outros na sociedade possibilita atuar sobre essa realidade 
com base nos conhecimentos adquiridos. A partir do momento em que o indivíduo se valoriza e define metas de participação e mudança social, isso pode ser um fator de inclusão social. Dessa forma, o desenvolvimento psicossocial é um aspecto que deveria ser considerado numa política de inclusão, como a regulamentada pelo Decreto $n^{0}$ 7.234/2010.

Nessa perspectiva, em 2012, o Fórum Nacional de Pró-reitores de Assuntos Comunitários e Estudantis (Fonaprace), que tem atuado na construção e aprimoramento do Programa de Assistência Estudantil desde a década de 1980, apontou alguns desafios a serem considerados na elaboração do planejamento estratégico da Associação Nacional dos Dirigentes das Instituições Federais de Ensino Superior (Andifes), dentre elas:

1) Composição e recomposição das equipes de profissionais para operacionalizar as ações da Política de Assistência Estudantil nas IFES, por exemplo, aumento do quadro de assistentes sociais, pedagogos, psicólogos, técnicos educacionais e técnicos-administrativos;

2) Fortalecimento da assistência estudantil a partir da relevância das Pró-Reitorias de Assuntos Estudantis e Comunitários, com vistas à criação de Pró-Reitorias específicas em todas as IFES de forma uniforme no que concerne à estrutura administrativa;

3) Implantação e ampliação de políticas de promoção e de assistência integral à saúde dos estudantes. Incluir, em caráter emergencial e prioritário, programas de prevenção e redução de danos ao uso indevido de álcool e outras drogas, com o objetivo de proporcionar qualidade de vida e saúde integral aos estudantes universitários [...]. (FONAPRACE, 2012, p. 71).

Observa-se o foco no fortalecimento das equipes que operacionalizam o programa e na ampliação das ações para atender questões relacionadas à saúde dos estudantes. Atualmente, para gestar e executar o Programa de Assistência Estudantil, as IFES contam com equipes técnicas multiprofissionais, compostas principalmente por assistentes sociais, psicólogos, pedagogos, enfermeiros, nutricionistas, dentre outros profissionais que tenham relação com o atendimento aos discentes, de acordo com a política de cada instituição. A composição da equipe técnica está descrita no Plano Nacional de Assistência Estudantil elaborado pelo Fonaprace em 2007.

Especialmente os assistentes sociais e os psicólogos são desafiados cotidianamente a fazer o elo entre discentes, famílias, docentes e outros sujeitos pertencentes ao contexto educacional, tendo em vista as especificidades técnicas desses profissionais, observadas nos códigos de ética profissional de ambos. Os princípios fundamentais do código de ética dos assistentes sociais ressaltam:

I. Reconhecimento da liberdade como valor ético central e das demandas políticas a ela inerentes - autonomia, emancipação e plena expansão dos indivíduos sociais; [...] III. Ampliação e consolidação da cidadania [...]; V. Posicionamento em favor da equidade e justiça social, que assegure universalidade de acesso aos bens e serviços relativos aos programas e políticas sociais [...]; VI. Empenho na eliminação de todas as formas de preconceito, incentivando o respeito à diversidade, à participação de grupos socialmente discriminados e à discussão das diferenças; VII. Garantia do pluralismo, através do respeito às correntes profissionais democráticas existentes e suas expressões teóricas [...]. (CFESS, 2011, p. 23-24). 
É perceptível a ligação entre a profissão do serviço social com a função social da escola na sociedade contemporânea. Libâneo (2012), ao discorrer sobre autonomia, emancipação, plena expansão dos indivíduos sociais e consolidação da cidadania, remete-nos aos conceitos de desenvolvimento humano, ações socioeducativas amplas, atendimento das diferenças individuais, sociais, integração social, convivência entre diferentes e o compartilhamento de culturas como condições que devem ser consideradas num novo tipo de escola.

0 código de ética dos psicólogos também apresenta várias prerrogativas condizentes com o novo tipo de escola descrito por Libâneo, Morin e outros autores aqui abordados. Destacam-se:

I. 0 psicólogo baseará o seu trabalho no respeito e na promoção da liberdade, da dignidade, da igualdade e da integridade do ser humano, apoiado nos valores que embasam a Declaração Universal dos Direitos Humanos.

II. 0 psicólogo trabalhará visando promover a saúde e a qualidade de vida das pessoas e das coletividades e contribuirá para a eliminação de quaisquer formas de negligência, discriminação, exploração, violência, crueldade e opressão.

III. 0 psicólogo atuará com responsabilidade social, analisando crítica e historicamente a realidade política, econômica, social e cultural. (CFP, 2005, p. 7).

Uma conquista recente da assistência estudantil brasileira foi a aprovação da Lei $n^{\circ} 13.935$, de 11 de dezembro de 2019, que dispõe sobre a prestação de serviços de psicologia e de serviço social nas redes públicas da educação básica (BRASIL, 2019), que tem muito a contribuir para a educação brasileira. É válido destacar que a referida lei foi vetada pela Presidência da República, posteriormente promulgada pelo Congresso Nacional após a derrubada do veto presidencial, o que reforça a necessidade de transformar a atual Pnaes numa política de Estado, e não de governo.

\section{Possibilidades de atuação dos profissionais da assistência estudantil}

0 processo de construção do Programa de Assistência Estudantil ocorreu a partir de várias concepções. Os diversos contextos sociopolíticos e segmentos sociais em que se desenvolveram as discussões em torno do tema favoreceram a emersão dessas múltiplas conceituações e inviabiliza um consenso no estabelecimento da noção de assistência estudantil (DUTRA; SANTOS, 2017).

Para Dutra e Santos (2017), há em campo a disputa de concepções de assistência estudantil mais restritas ou mais seletivas, com público-alvo focado apenas nos estudantes em situação de vulnerabilidade socioeconômica, em contraposição às concepções mais abrangentes, numa perspectiva mais universal. Num panorama amplo, o programa não deve se limitar à elaboração e execução de mecanismos destinados apenas à população de baixa renda, mas deve se atentar também a princípios de atendimento universal, tendo em vista que os fatores sociais, pessoais, relacionais e acadêmicos influenciam a permanência 
no curso, o desempenho acadêmico e o desenvolvimento psicossocial dos estudantes universitários (ANDRADE, 2017; FIGUEIREDO; SALLES, 2017; SILVA; NOGUEIRA, 2016).

De acordo com Taufick (2014), na constituição do Pnaes (Decreto $n^{\circ} 7.234 / 2010$ ) existe uma intencionalidade em constituir ações complementares às atividades pedagógicas que ampliem a formação do indivíduo mediante a oferta de ações voltadas a saúde, cultura, esporte e inclusão digital. 0 artigo $1^{\circ}$ do decreto discorre sobre a finalidade do programa em ampliar as condições de permanência dos jovens na educação superior pública federal (no caso dos institutos, inicia-se o atendimento desde o nível básico até a pós-graduação), o que contemplaria as várias possibilidades de ações com vistas a esse fim. Ainda de acordo com o Pnaes, em seu artigo $2^{\circ}$, constam os seguintes objetivos:

I - democratizar as condições de permanência dos jovens na educação superior pública federal; II - minimizar os efeitos das desigualdades sociais e regionais na permanência e conclusão da educação superior; III - reduzir as taxas de retenção e evasão; e IV - contribuir para a promoção da inclusão social pela educação. (BRASIL, 2010, grifo nosso).

Os objetivos do programa ratificam as possibilidades de ações com foco em áreas além da econômica. 0 artigo $3^{\circ}$ preconiza que tais ações deverão ser articuladas com as ações de ensino, pesquisa e extensão. É importante considerar a interdependência entre as áreas de ações do Pnaes, pois apresentam necessidades que precisam ser supridas simultaneamente. Ao tempo que se atende carências relacionadas à moradia, por exemplo, não se pode deixar de considerar a necessidade de alimentação. Qualquer área descoberta pode coincidir com a evasão do estudante (RECKTENVALD et al., 2018).

Apesar de o Pnaes ser um programa nacional, cada instituição de ensino superior tem autonomia na gestão da política e utilização dos recursos de acordo com suas necessidades e particularidades locais, considerando as áreas expostas no decreto.

Em 2014, Taufick publicou um estudo sobre as políticas de assistência estudantil de trinta institutos federais do Brasil e analisou alguns pontos-chave dos documentos. Em relação aos objetivos das políticas analisadas, observamos que possuem vinculação com os direitos sociais e com o atendimento integral dos estudantes, contemplando aspectos sociais, acadêmicos, de saúde, de cultura e de formação cidadã. "Muitas instituições ousam creditar à assistência estudantil o papel de fornecedor de uma gama de benefícios que promovem desde a formação para a cidadania, até a participação na vida acadêmica e política da instituição" (TAUFICK, 2014, p. 198).

Em complementação aos estudos de Taufick (2014), analisamos os documentos que regulamentam a assistência estudantil nos IFs da região Norte (Acre, Amapá, Amazonas, Pará, Rondônia, Roraima, Tocantins), com foco na composição das equipes de atendimento e nas atribuições descritas.

Observamos que todos os institutos têm regulamentação para assistência estudantil aprovada por Conselho Superior, cinco delas datam dos anos de 2018 a 2020. Dos sete IFs analisados, apenas um apresenta, em sua regulamentação, a política focada essencialmente em auxílios financeiros. Por sua vez, em quatro deles são evidenciados programas com eixo de atendimento universal, ou seja, com atendimentos pensados para além de auxílios 
financeiros e, em outros dois IFs, embora não esteja explicitamente descrito, fica claro que seu foco está voltado para além das ações relacionadas às questões econômicas, compreendendo programas de atenção e promoção da saúde, apoio psicológico e pedagógico.

No que tange à composição da equipe, seis IFs preveem, em sua política, uma equipe multiprofissional, composta por assistente social, psicólogo, pedagogo e/ou técnico em assuntos educacionais. Além desses profissionais, são elencados médicos, enfermeiros, nutricionistas, dentistas, dentre outros de áreas afıns em dois institutos. Apenas em um não consta descrição da equipe que atuará na política de assistência estudantil institucional.

Cabe destacar que não foi observada na política de dois IFs a descrição das ações da equipe envolvida na assistência estudantil. Em outras cinco políticas, identificamos ações a serem desenvolvidas que se relacionam à perspectiva universal e, consequentemente, possibilita o desenvolvimento educacional omnilateral, a saber:

- Ações de promoção social e formação cidadã dos estudantes;

- Ações que visem integrar o tripé do processo educacional aluno, escola, família;

- Campanhas e palestras educativas que contribuam para o fortalecimento intelectual, social, político e cultural dos discentes;

- Atendimentos de alunos e/ou responsáveis, em situações específicas;

- Ações de formação e prevenção relativas ao uso e abuso de substâncias psicoativas, vulnerabilidade a doenças sexualmente transmissiveis, doenças crônicas, gravidez e paternidade precoces, dentre outros temas;

- Serviço psicológico educacional: busca o desenvolvimento humano, como foco na qualidade de vida do estudante;

- Serviço técnico-pedagógico: avalia as questões institucionais intervenientes na aprendizagem dos estudantes e promove atividades diversificadas para contribuir com o desenvolvimento das múltiplas inteligências;

- Serviço de acompanhamento social: estimula a vivência e o aprendizado do processo democrático na instituição, promove o fortalecimento da cidadania, incentiva a integração e participação da família dos estudantes no contexto acadêmico;

- Serviço de assistência básica à saúde: atendimentos individuais, palestras educativas, oficinas, campanhas, dentre outras ações;

- Ações de atenção à saúde e apoio biopsicossocial;

- Ações voltadas ao atendimento do estudante com baixo desempenho acadêmico, com necessidades educacionais específicas ou em situação de vulnerabilidade socioeconômica, visando a conclusão do curso; e

- Educação para a diversidade.

É válido reafirmar que vários dos profissionais técnicos que compõem a equipe de assistência estudantil dispõem de leis de regulamentação profissional ou códigos de ética que apontam competências e atribuições de maneira genérica e que têm vínculo direto com o trabalho desempenhado no ambiente educacional. 


\section{Considerações finais}

Permitem reconhecer a importância da assistência estudantil e as possibilidades de atuação diversificada no processo educacional: as discussões sobre a formação integral que consideram todos os aspectos do indivíduo; o entendimento de que todos os profissionais presentes no ambiente escolar têm função importante no processo educacional formal; as prerrogativas do decreto que regem o Programa de Assistência Estudantil nos institutos e universidades federais; e as especificidades dos profissionais que compõem as equipes de gestão e execução do programa.

Observamos a concorrência de basicamente duas concepções sobre a atuação da assistência estudantil. Uma de caráter seletivo, portanto restritiva, de cunho apenas assistencial financeiro, que, sem deixar de reconhecer sua importância, pode refletir em processos educacionais reprodutores do status quo da sociedade de classes. Outra, com uma concepção universalizante, a qual acreditamos poder colaborar com o processo de emancipação, uma vez que visa atender o estudante em sua multidimensionalidade (econômica, social, acadêmica, desenvolvimento humano, dentre outros).

Ao analisar os regulamentos de assistência estudantil dos IFs situados na região Norte, fica nítida a intenção em desenvolver ações complementares ao ensino que contribuam para a formação cidadã dos discentes para além do apoio financeiro. Entretanto, indagamos se essas ações e propósitos estão realmente em execução.

Tendo em vista as constantes mudanças que ocorrem em nível social e político, este estudo não tem a pretensão de sanar as questões sobre as possibilidades de atuação da assistência estudantil no processo educacional, o que implica na necessidade de novos estudos que possam contribuir com delineamentos norteadores do trabalho dos educadores atuantes nessa área.

\section{Referências}

ANDRADE, Ana Maria Jung de; TEIXEIRA, Marco Antônio Pereira. Áreas da política de assistência estudantil: relação com desempenho acadêmico, permanência e desenvolvimento psicossocial de universitários. Avaliação, Campinas, v. 22, n. 2, p. 512-528, 2017.

ANTUNES, Evelise Dias. Assistência estudantil nos institutos federais: da política à implementação. 2018. Dissertação (Mestrado em Educação) - Universidade Estadual de Campinas, Campinas, 2018.

BEZERRA, Zedeki Fiel et al. Comunidade e escola: reflexões sobre uma integração necessária. Educar em Revista, Curitiba, n. 37, p. 279-291, 2010.

BOCK, Ana Mercês Bahia et al. Significações sobre escola e projeto de futuro em uma sociedade desigual. In: AGUIAR, Wanda Maria Junqueira de; BOCK, Ana Mercês Bahia (org.). A dimensão subjetiva do processo educacional. São Paulo: Cortez, 2016. p. 229-248.

BORGES, Liliam Faria Porto. Educação, escola e humanização em Marx, Engels e Lukács. Revista Educação em Questão, Natal, v. 55, n. 45, p. 101-126, 2017. 
BRASIL. Congresso Nacional. Projeto de Lei $n^{0}$ 1.217, de abril de 2015. Dispõe sobre o Programa Nacional de Assistência Estudantil - PNAES. Brasília, DF: Câmara dos Deputados, 2015. Disponível em: https://www.camara.leg.br/proposicoesWeb/fichadetramitacao?idProposica0=1215522. Acesso em: 28 fev. 2020.

BRASIL. [Constituição (1934)]. Constituição da República dos Estados Unidos do Brasil, de 16 de julho de 1934. Diário Oficial da União, Rio de Janeiro, 16 jul. 1934. Disponível em: http://www.planalto.gov.br/ ccivil_03/constituicao/constituica034.htm. Acesso em: 15 mar. 2020.

BRASIL. [Constituição (1946)]. Constituição dos Estados Unidos do Brasil, de 18 de setembro de 1946. Diário Oficial da União, Rio de Janeiro, 19 set. 1946. Disponível em: http://www.planalto.gov.br/ccivil_03/ constituicao/constituica046.htm. Acesso em: 15 mar. 2020.

BRASIL. [Constituição (1988)]. Constituição da República Federativa do Brasil de 1988. Diário Oficial da União, Brasília, DF, 5 out. 1988. Disponível em: http://www.planalto.gov.br/ccivil_03/constituicao/ constituicao.htm. Acesso em: 22 nov. 2020.

BRASIL. Decreto n 7.234, de 19 de julho de 2010. Dispõe sobre o Programa Nacional de Assistência Estudantil - PNAES. Diário Oficial da União, Brasília, DF, 20 jul. 2010. Disponível em: http://www.planalto. gov.br/ccivil_03/_ato2007-2010/2010/decreto/d7234.htm. Acesso em: 15 jul. 2019.

BRASIL. Decreto n 19.851, de 11 de abril de 1931. [...] Estatuto das Universidades Brasileiras. Diário Oficial da União, Rio de Janeiro, 15 abr. 1931. Disponível em: https://www2.camara.leg.br/legin/fed/ decret/1930-1939/decreto-19851-11-abril-1931-505837-publicacaooriginal-1-pe.html. Acesso em: 15 jul. 2019.

BRASIL. Decreto n 69.927, de 13 de janeiro de 1972. Institui em caráter nacional, o Programa "Bolsa de Trabalho". Diário Oficial da União, Brasília, DF, 14 jan. 1972. Disponível em: https://www2.camara.leg. br/legin/fed/decret/1970-1979/decreto-69927-13-janeiro-1972-418292-publicacaooriginal-1-pe.html. Acesso em: 15 jul. 2019.

BRASIL. Lei n 4.024, de 20 de dezembro de 1961. Fixa as Diretrizes e Bases da Educação Nacional. Diário Oficial da União, Brasília, DF, 27 dez. 1961. Disponível em: https://www2.camara.leg.br/legin/fed/lei/19601969/lei-4024-20-dezembro-1961-353722-publicacaooriginal-1-pl.html. Acesso em: 2 fev. 2020.

BRASIL. Lei $n^{0}$ 5.692, de 11 de agosto de 1971. Fixa as Diretrizes e Bases para o ensino de $1^{\circ}$ e $2^{\circ}$ graus, e dá outras providências. Diário Oficial da União, Brasília, DF, 12 ago. 1971. Disponível em: https://www2. camara.leg.br/legin/fed/lei/1970-1979/lei-5692-11-agosto-1971-357752-publicacaooriginal-1-pl.html. Acesso em: 2 fev. 2020.

BRASIL. Lei no 9.394, de 20 de dezembro de 1996. Estabelece as Diretrizes e Bases da Educação Nacional. Diário Oficial da União, Brasília, DF, 23 dez. 1996. Disponível em: http://www.planalto.gov.br/ccivil_03/ leis/l9394.htm. Acesso em: 2 fev. 2020. 
BRASIL. Lei n 13.935 , de 11 de dezembro de 2019. Dispõe sobre a prestação de serviços de psicologia e de serviço social nas redes públicas de educação básica. Diário Oficial da União, Brasília, DF, 12 dez. 2019. Disponível em: https://www2.camara.leg.br/legin/fed/lei/2019/lei-13935-11-dezembro-2019789559-publicacaooriginal-159616-pl.html. Acesso em: 22 nov. 2020.

BRASIL. Ministério da Educação. Por uma política de valorização dos trabalhadores em educação: em cena, os funcionários da escola. Brasília, DF: Ministério da Educação, 2004. Disponível em: http://portal. mec.gov.br/seb/arquivos/pdf/em_cena.pdf. Acesso em: 4 nov. 2019.

BRASIL. Ministério da Educação. Portaria Normativa $n^{0}$ 39, de 12 de dezembro de 2007. Institui 0 Programa Nacional de Assistência Estudantil - PNAES. Brasília, DF: Ministério da Educação, 2007.

CFESS. Conselho Federal de Serviço Social. Código de ética do/a assistente social. 10. ed. rev. atual. Brasília, DF: CFESS, 2011. Disponível em: http://www.cfess.org.br/arquivos/CEP_CFESS-SITE.pdf. Acesso em: 18 nov. 2019.

CFP. Conselho Federal de Psicologia. Código de ética profissional do psicólogo. Brasília, DF: CFP, 2005. Disponível em: https://site.cfp.org.br/wp-content/uploads/2012/07/codigo-de-etica-psicologia.pdf. Acesso em: 18 nov. 2019.

COSTA, Maria Adélia; COUTINHO, Eduardo Henrique Lacerda. Educação profissional e a reforma do ensino médio: lei nº 13.415/2017. Educação \& Realidade, Porto Alegre, v. 43, n. 4, p. 1633-1652, 2018.

DUTRA, Natália Gomes dos Reis; SANTOS, Maria de Fátima de Souza. Assistência estudantil sob múltiplos olhares: a disputa de concepções. Ensaio, Rio de Janeiro, v. 25, n. 94, p. 148-181, 2017.

FIGUEIRED0, Natália Gomes da Silva; SALLES, Denise Medeiros Ribeiro. Educação profissional e evasão escolar em contexto: motivos e reflexões. Ensaio, Rio de Janeiro, v. 25, n. 95, p. 356-392, 2017.

FONAPRACE. Fórum Nacional de Pró-Reitores de Assuntos Comunitários e Estudantis. Revista Comemorativa 25 Anos: histórias, memórias e múltiplos olhares. Uberlândia: Fonaprace, 2012. Disponível em: http://www.proae.ufu.br/sites/proae.ufu.br/files/media/arquivo/revista_fonaprace_25_anos.pdf Acesso em: 17 nov. 2019.

IFAC. Instituto Federal do Acre. Resolução n 35, de 21 de junho de 2018. Dispõe sobre a Política de Assistência Estudantil do Instituto Federal de Educação, Ciência e Tecnologia do Acre. Rio Branco: Conselho Superior, 2018.

IFAM. Instituto Federal do Amazonas. Resolução nº 13-CONSUP/IFAM, de 9 de junho de 2011. Institui a Política de Assistência Estudantil no âmbito do IFAM. Manaus: Conselho Superior, 2011.

IFAP. Instituto Federal do Amapá. Resolução n³1/2019 CONSUP/IFAP, de 22 de março de 2019. Aprova a reformulação da política de assistência estudantil, do Instituto Federal de Educação, Ciência e Tecnologia do Amapá - IFAP. Macapá: Conselho Superior, 2019. 
IFPA. Instituto Federal do Pará. Resolução n 7/2020-CONSUP, de 8 de janeiro de 2020. Regulamenta a Política de Assistência Estudantil no Instituto Federal de Educação, Ciência e Tecnologia do Pará. Belém: Conselho Superior, 2020.

IFRO. Instituto Federal de Rondônia. Resolução n 23/REIT - CONSUP/IFR0, de 26 de março de 2018. Dispõe sobre a aprovação do Regulamento dos Programas de Assistência Estudantil (REPAE) do Instituto Federal de Educação, Ciência e Tecnologia de Rondônia - IFRO. Porto Velho: Conselho Superior, 2018.

IFRR. Instituto Federal de Roraima. Resolução nº 486 - Conselho Superior, de 14 de janeiro de 2020. Aprova ad referendum o regulamento da Política de Assuntos Estudantis no Instituto Federal de Educação, Ciência e Tecnologia de Roraima (IFRR). Boa Vista: Conselho Superior, 2020.

IFTO. Instituto Federal do Tocantins. Resolução n 22/2014/CONSUP/IFTO, de 8 de agosto de 2014. Dispõe sobre a implantação da Política de Assistência Estudantil no âmbito do IFT0 e dá outras providências. Palmas: Conselho Superior, 2014.

LIBÂNEO, José Carlos. 0 dualismo perverso da escola pública brasileira: escola do conhecimento para os ricos, escola do acolhimento social para os pobres. Educação e Pesquisa, São Paulo, v. 38, n. 1, p. 13$28,2012$.

MAGALHÃES, Josiane. 0 processo educacional formal e a construção do social determinando a construção da consciência. Revista da Faculdade de Educação, Cáceres, v. 2, n. 2, p. 153-164, 2004. Disponível em: https://periodicos.unemat.br/index.php/ppgedu/article/view/3465/2758. Acesso em: 28 out. 2019.

MORIN, Edgar. Os sete saberes necessários à educação do futuro. Tradução Catarina Eleonora F. da Silva e Jeanne Sawaya. 2. ed. São Paulo: Cortez. 2011.

NASCIMENTO, Ana Paula Leite. Uma análise das ações de assistência estudantil no contexto do Instituto Federal de Educação, Ciência e Tecnologia de Sergipe. 2014. Dissertação (Mestrado em Serviço Social) - Universidade Federal de Sergipe, São Cristóvão, 2014. Disponível em: https://ri.ufs.br/ handle/riufs/6189. Acesso em: 3 out. 2019.

RECKTENVALD, Marcelo; MATTEl, Lauro; PEREIRA, Vilmar Alves. Avaliando o Programa Nacional de Assistência estudantil (PNAES) sob a ótica das epistemologias. Avaliação, Campinas, v. 23, n. 2, p. 405423, 2018.

SILVA, Maria das Graças Martins da; NOGUEIRA, Patrícia Simone. A permanência dos estudantes na educação superior para além da assistência estudantil. Revista da Faculdade de Educação, Cáceres, v. 25, n. 1, p. 111-129, 2016. Disponível em: https://periodicos.unemat.br/index.php/ppgedu/article/ view/3944/3137. Acesso em: 28 out. 2019.

TAUFICK, Ana Luiza de Oliveira Lima. Análise da política de assistência estudantil dos Institutos Federais de Educação, Ciência e Tecnologia. Revista Brasileira de Política e Administração da Educação, Brasília, DF, v. 30, n. 1, p. 181-201, 2014. Disponível em: https://seer.ufrgs.br/rbpae/article/view/50020/31328. Acesso em: 1 out. 2019. 
ZABALA, Antoni. A prática educativa: como ensinar. Porto Alegre: Artmed, 1998.

Recebido em: 15.05.2020

Revisado em: 01.07.2020

Aprovado em: 21.07.2020

Priscila da Silva Soares é mestranda em educação profissional e tecnológica pelo Instituto Federal do Acre (IFAC), especialista em educação, diversidade e cidadania e assistente social no IFAC.

Cledir de Araújo Amaral é docente do Programa de Pós-graduação em Mestrado Profissional em Educação Profissional e Tecnológica do Instituto Federal do Acre (IFAC), doutor em saúde pública pela Escola Nacional de Saúde Pública Sérgio Arouca (Ensp/Fiocruz) e docente de educação física no IFAC. 